\title{
New crystallographic relationships in biogenic aragonite: the crossed-lamellar microstructures of mollusks
}

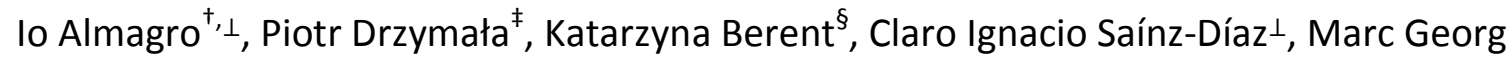
Willingerll, Jan Bonarski ${ }^{\ddagger}$ and Antonio G. Checa*, ${ }^{+}, \perp$

${ }^{\dagger}$ Departamento de Estratigrafía y Paleontología, Facultad de Ciencias, Universidad de Granada, Avenida Fuentenueva s/n, 18071 Granada, Spain,

IInstituto Andaluz de Ciencias de la Tierra (CSIC), Avda. de Las Palmeras no 4, 18100. Armilla, Granada, Spain

${ }^{\ddagger}$ Institute of Metallurgy and Materials Science of the Polish Academy of Sciences, 25 Reymonta Str., 30-059 Krakow,

Poland

${ }^{\S}$ AGH University of Science and Technology, Academic Centre for Materials and Nanotechnology, al. Mickiewicza 30, 30059 Kraków, Poland

"Fritz Haber Institute of the Max-Planck-Society, Department of Inorganic Chemistry. Faradayweg 4-614195 Berlin, Germany

\section{SUPPORTING INFORMATION \\ Contents}

Table S1

Table S2

Figure S1

Figure S2

Figure S3 6S

Figure S4 $7 S$

Figure S5 85

Figure S6 9S

Figure S7 $10 S$

Figure S8 
Table S1. List of bivalve species examined

\begin{tabular}{|c|c|c|}
\hline Subclass & Order & Species \\
\hline rotobranchia & Nuculanoida & Megayoldia thraciaeformis (Storer, 1838) \\
\hline teriomorphia & Arcoida & Arca noae (Linnaeus, 1758) \\
\hline “ & “ & Glycymeris glycymeris (Linnaeus,1758) \\
\hline “ & “ & Glycymeris nummaria (Linnaeus, 1758) \\
\hline “ & Limoida & Lima lima (Linnaeus, 1758) \\
\hline “ & Pectinoida & Plicatula muricata (G. B. Sowerby II, 1873) \\
\hline “ & Pectinoida & Spondylus sinensis (Schreibers, 1793) \\
\hline Heterodonta & Carditoida & Eucrassatella decipiens (Reeve, 1842) \\
\hline “ & Anomalodesmata & Cuspidaria nobilis (A. Adams, 1864) \\
\hline “ & Lucinoida & Phacoides pectinatus (Gmelin, 1791) \\
\hline “ & Myoida & Pholas dactylus (Linnaeus, 1758) \\
\hline “ & “ & Corbula sinensis (Bernard, Cai \& Morton, 1993) \\
\hline “ & Veneroida & Laevicardium oblongum (Gmelin, 1791) \\
\hline “ & “ & Tridacna gigas (Linnaeus, 1758) \\
\hline “ & “ & Donax deltoides (Lamarck, 1818) \\
\hline “ & “ & Lioconcha castrensis (Linnaeus, 1758) \\
\hline “ & “ & Periglypta albocancellata (Huber, 2010) \\
\hline “ & “ & Circe rivularis (Born, 1778) \\
\hline “ & “ & Callista chione (Linnaeus, 1758) \\
\hline “ & “ & Tellina foliacea (Linnaeus, 1758) \\
\hline
\end{tabular}


Table S2. List of gastropod species examined

Subclass

Order

Species

Patellogastropoda Patelloidea

Cymbula safiana (Lamarck, 1819)

Neritimorpha Cycloneritimorpha Nerita undata (Linnaeus, 1758)

Vetigastropoda Fissurelloidea

Diodora graeca (Linnaeus, 1758)

Fissurella crassa (Lamarck, 1822)

Phasianelloidea

Tricolia capensis (Dunker, 1846)

Trochoidea

Cittarium pica (Linnaeus, 1758)

II

Tectus pyramis (Born, 1778)

Caenogastropoda Littorinimorpha

“

Heterobranchia Eupulmonata
Semicassis bisulcata (Schubert \& Wagner, 1829)

Semicassis granulata (Born, 1778)

Littorina littorea (Linnaeus, 1758)

Naticarius hebraeus (Martyn, 1786)

Naticidae sp.

Lobatus gigas (Linnaeus, 1758)

Strombus.pugilis (Linnaeus, 1758)

Turritella duplicata (Linnaeus, 1758)

Conus marmoreus (Linnaeus, 1758)

Oliva reticulata (Röding, 1798)

Achatina fulica (Bowdich,1822)

Eobania vermiculata (Müller,1774)

Ryssota otaheiata (Férussac, 1821) 
BIVALVES
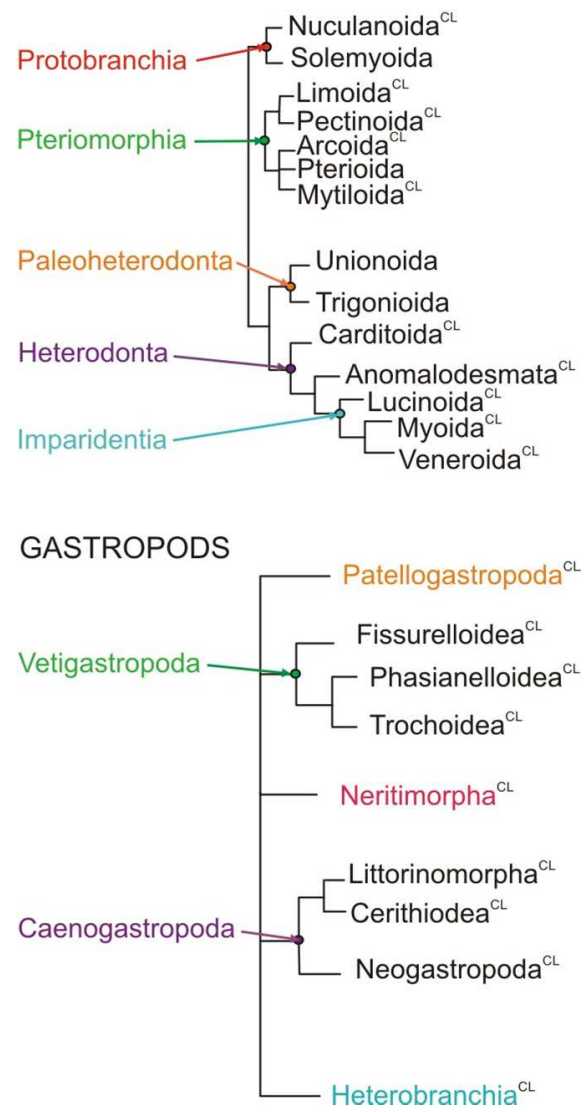

Figure S1. Phylogenetic diagrams of the main groups of bivalves and gastropods. Superscript CL indicates that the group contains representatives with CL layers. Schemes for bivalves modified from: (1) González, V. L.; Giribet, G. Zool. Scripta 2015, 44, 41-58, with additions from (2) Sharma, P. P.; González, V. L.; Kawauchi, G. Y.; Andrade, S. C. S.; Guzmán, A.; Collins, T. M.; Glover, E. A.; Harper, E. M.;Healy, J. M.; Mikkelsen, P. M.; Taylor, J. D.; Bieler, R.; Giribet, G. Mol. Phylog. Evol. 2012, 65, 64-74. Scheme for gastropods modified from: (1) Zapata, F.; Wilson, N. G.; Howison, M.; Andrade, S. C. S.; Jörger, K. M.; Schrödl, M.; Goetz, F. E.; Giribet, G.; Dunn, C. W. Proc. R. Soc. B, 2014, 281, 20141739, with additions from (2) Hedegaard, C. J. Moll. Stud. 1997, 63, 369-377, and (3) Colgan, D. J.; Ponder, W. F.; Eggler, P. E. Zool. Scripta 2000, 29, 2963. 

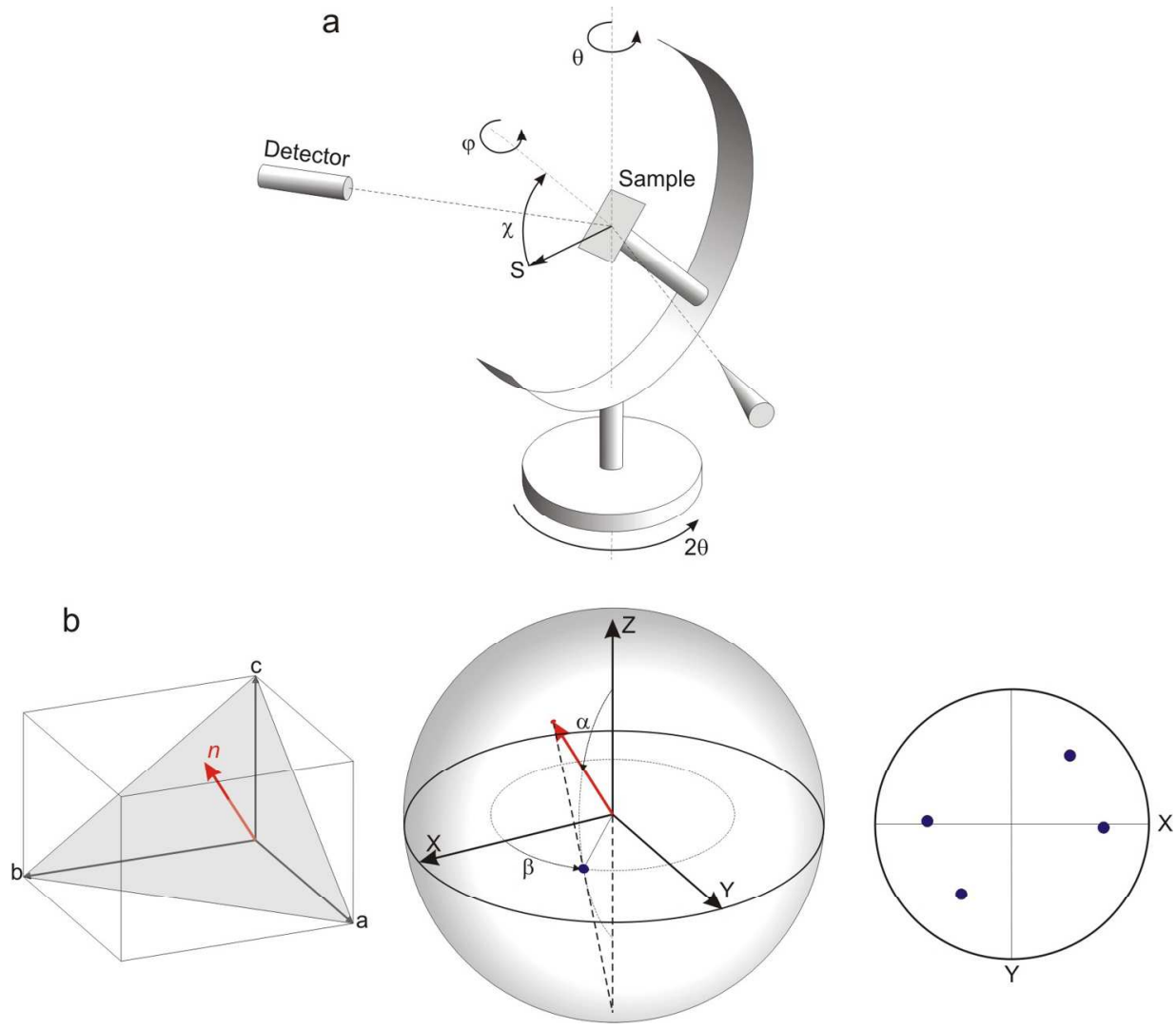

Figure S2. X-ray diffraction and associated pole figures. (a) Scheme of the Eulerian cradle. The axis of X-ray source, axis of detector and diffraction vector $S$ are in the horizontal plane and are defined by angles $\theta$ and $2 \theta$. The position of the sample with respect to diffraction vector $S$ is described by the tilt $(\chi)$ and rotation $(\varphi)$ angles. (b) Left, example of an orthorhombic crystal system (with a, b, c dimensions approximated to those of aragonite) and a crystallographic plane $(\mathrm{hkl})=(111)$ expressed in Miller indices. Red vector $n$ denotes normal to (111) plane (pole). Center, stereographic projection of vector $n$ on the $X-Y$ plane of the sample coordinate system (blue point). The angular position of $n(\alpha, \beta)$ corresponds to the position of the Euler cradle $(\chi, \varphi)$ in this measurement mode. Right, complete 111 pole figure for a single ideal crystal (only the poles in the upper hemisphere are represented). 

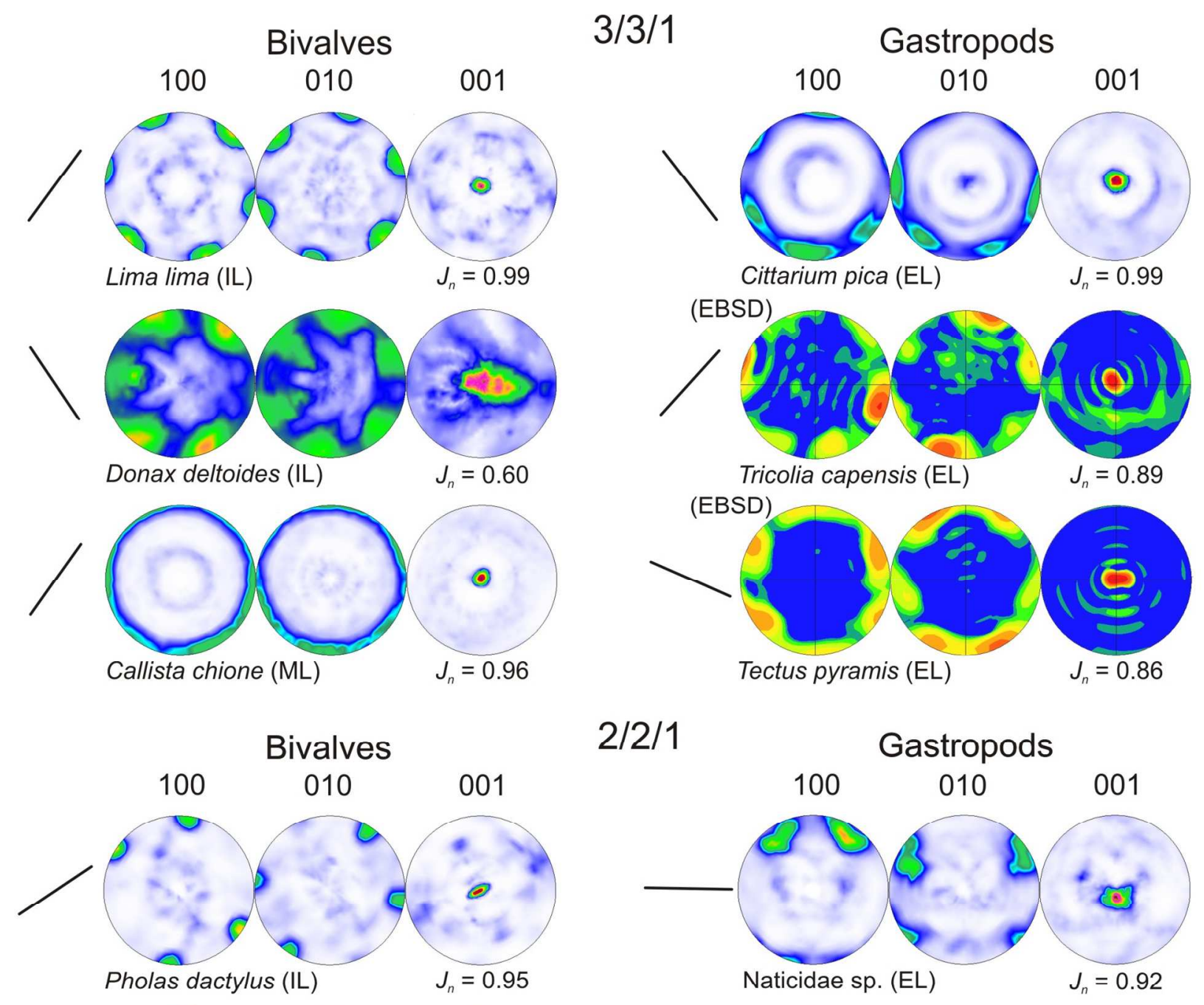

$2 / 2 / 1$

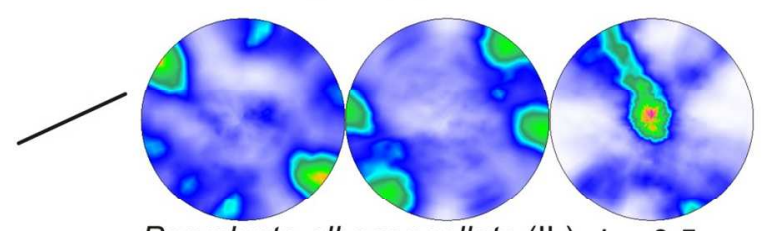

Peryglypta albocancellata (IL) $J_{n}=0.5$
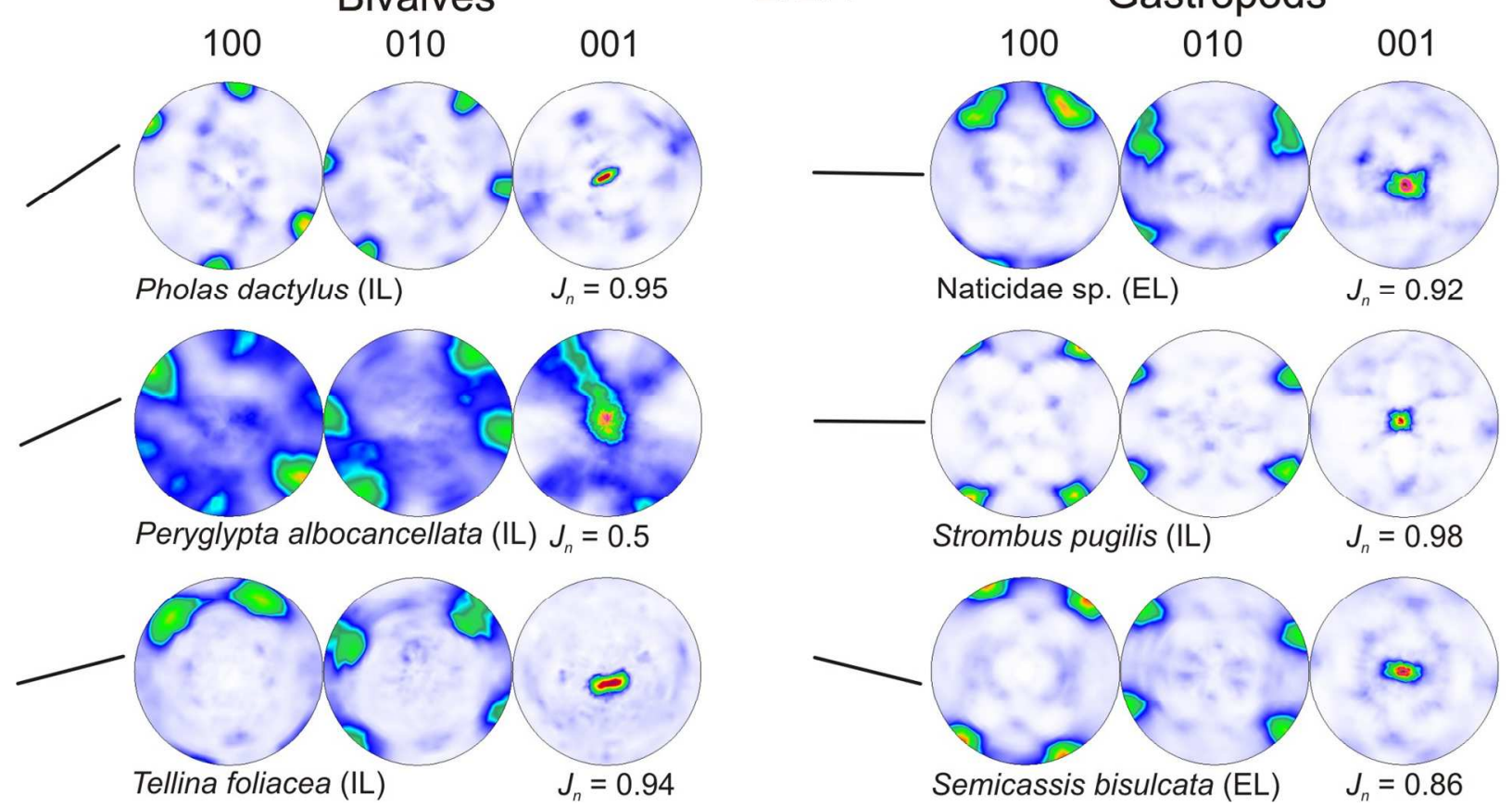

Figure S3. PFs of the molluscan species with $3 / 3 / 1$ and $2 / 2 / 1$ patterns. Bars on the left of PFs represent the orientation of the $1^{\text {st }} \mathrm{OL}$. $J n$ is the texture index. All XRD data, except when indicated. $\mathrm{EL}=$ external layer; $\mathrm{IL}=$ internal layer; $\mathrm{ML}=$ middle layer. 


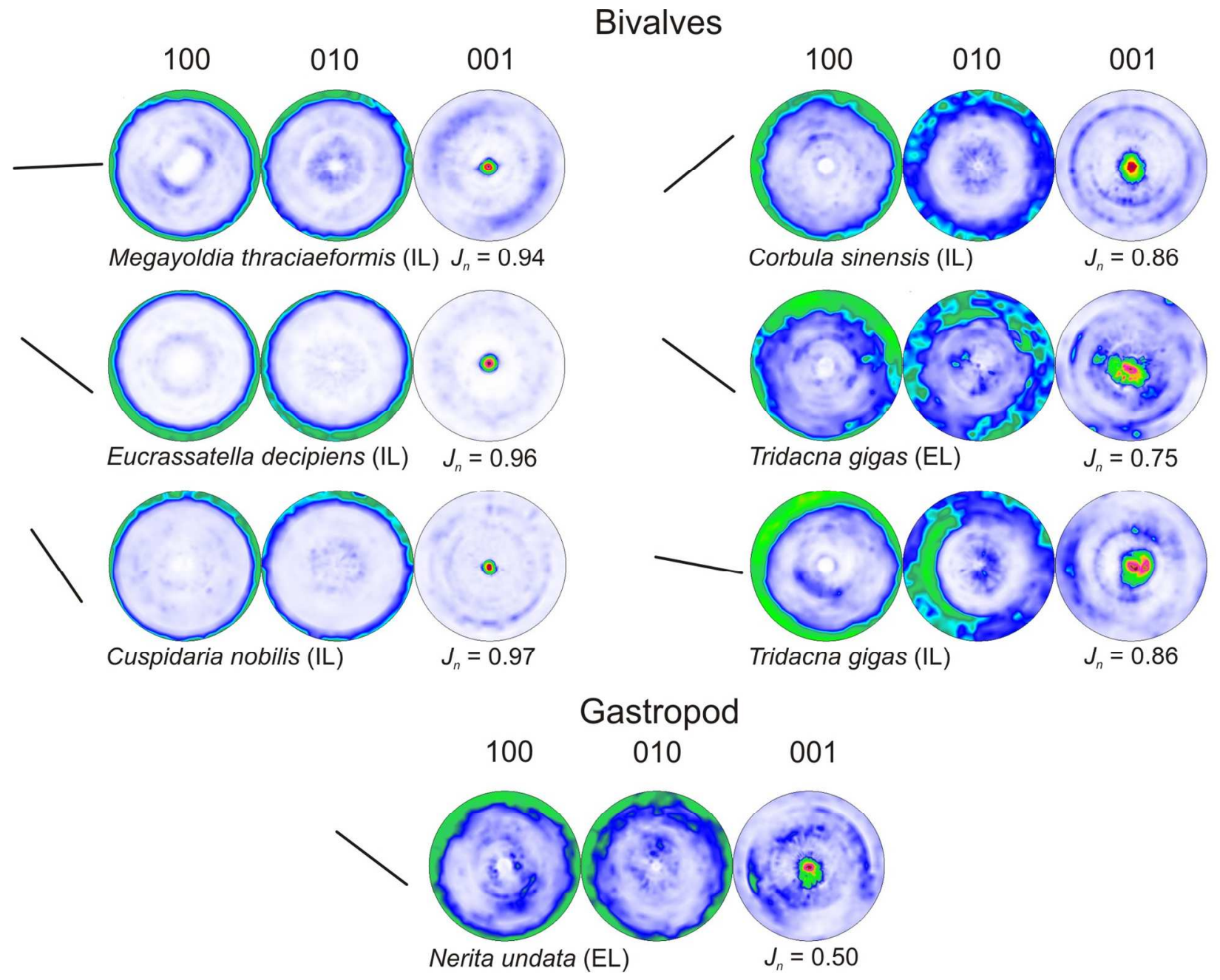

Figure S4. PFs of the molluscan species with $\infty / \infty / 1$ patterns (fiber texture). Bars on the left of $\mathrm{PFs}$ represent the orientation of the $1^{\text {st }} \mathrm{OL}$. $\mathrm{Jn}$ is the texture index. All XRD data. EL = external layer; IL = internal layer. 


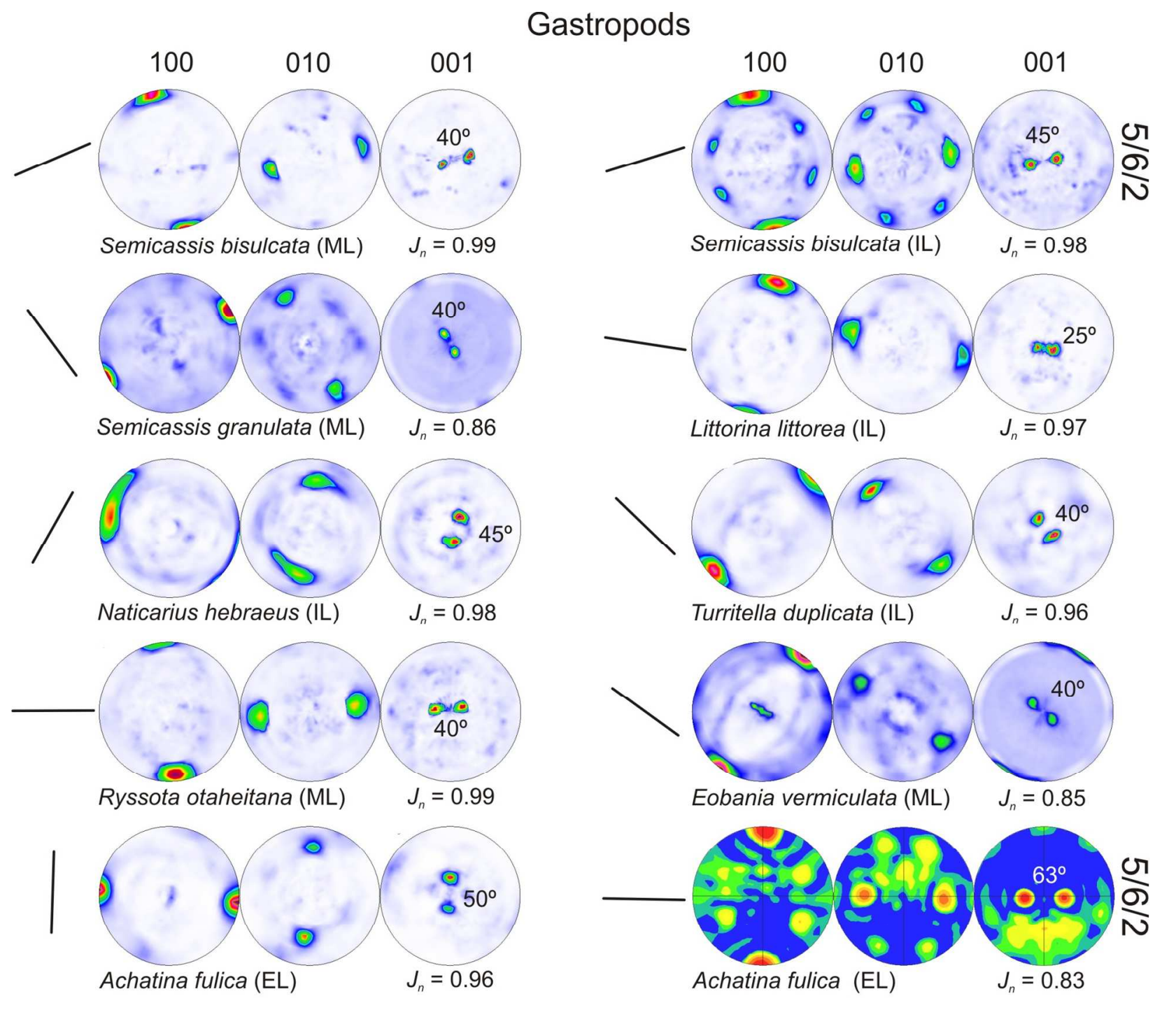

Figure S5. PFs of the molluscan species (all gastropods) with $1 / 2 / 2$ and $5 / 6 / 2$ patterns (indicated). Bars on the left of PFs represent the orientation of the $1^{\text {st }} \mathrm{OL}$. $\mathrm{Jn}$ is the texture index. All XRD data. $E L=$ external layer; $I L=$ internal layer; $M L=$ middle layer. 


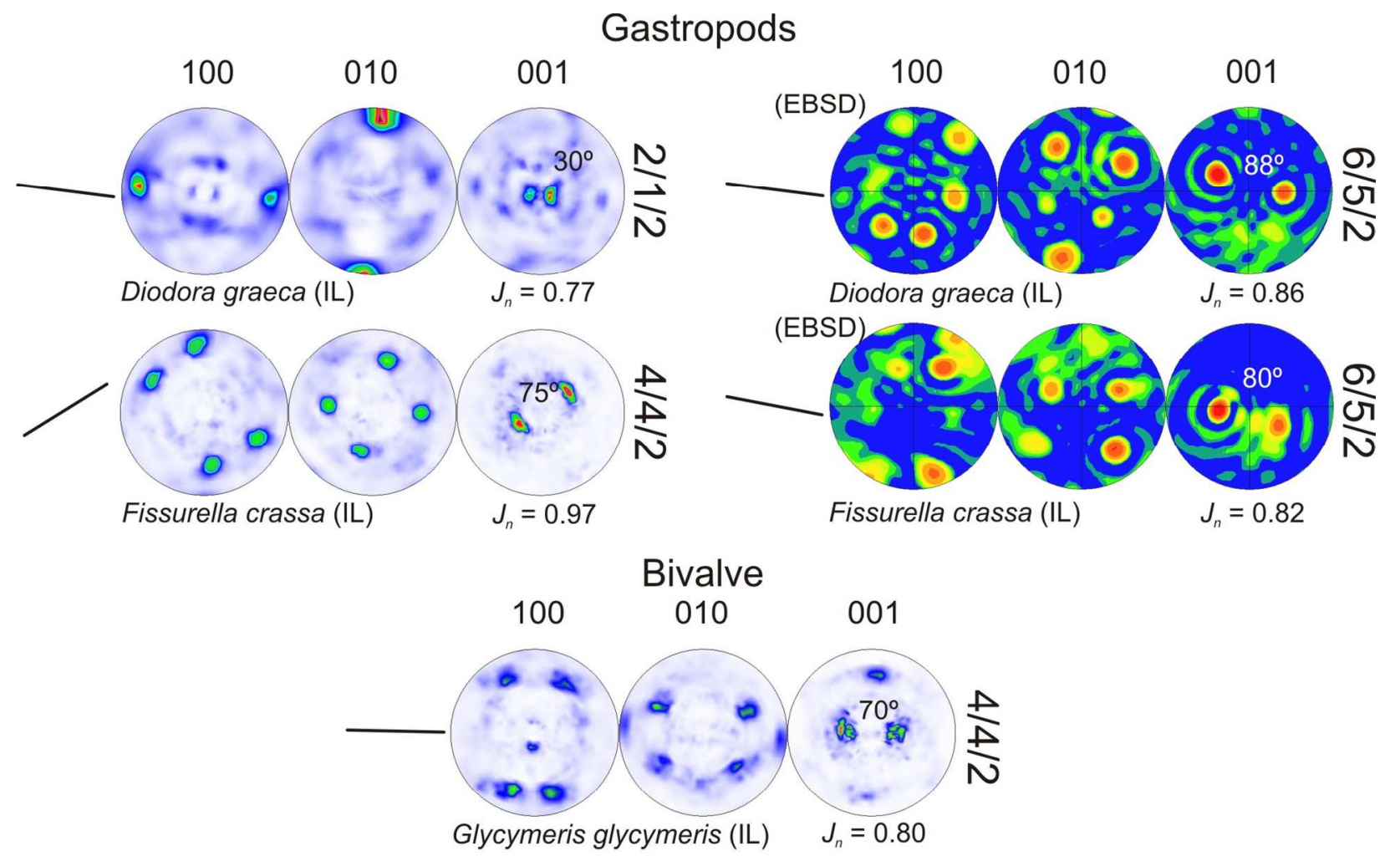

Figure S6. PFs of the molluscan species with $2 / 1 / 2,6 / 5 / 2$ and $4 / 4 / 2$ patterns (indicated). Bars on the left of PFs represent the orientation of the $1^{\text {st }} \mathrm{OL}$. $J n$ is the texture index. All XRD data, except when indicated. IL = internal layer. 


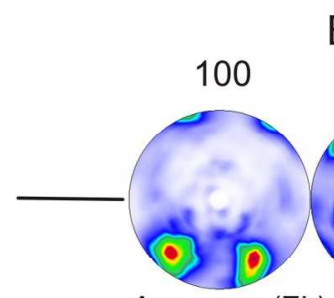

Arca noae (EL)

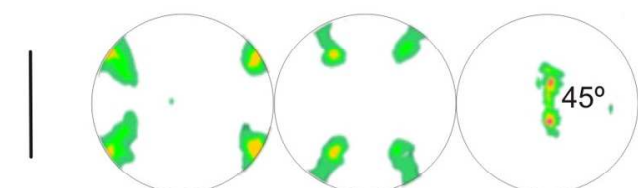

Glycymeris nummaria (EL) $\quad J_{n}=0.92$
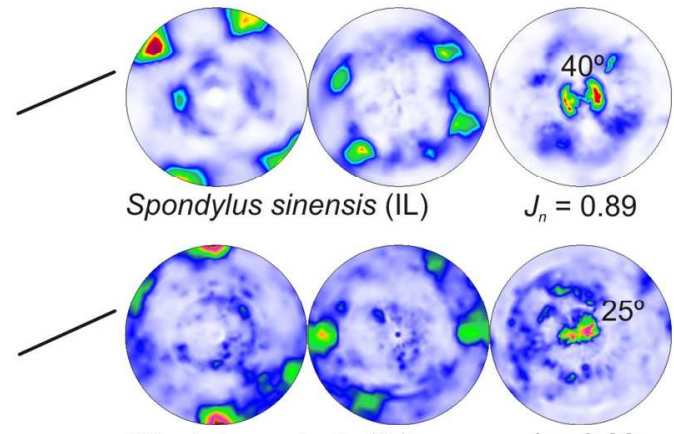

Plicatula muricata (IL)
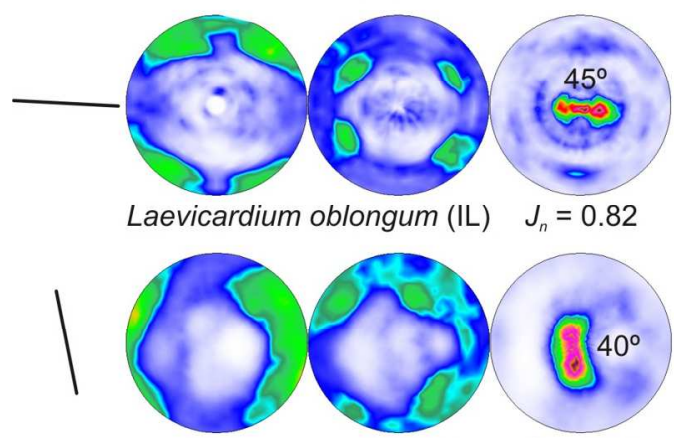

Lioconcha castrensis (EL)

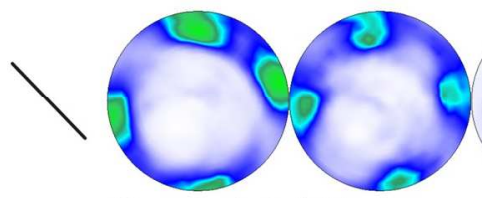

Circe rivularis $(\mathrm{EL})$

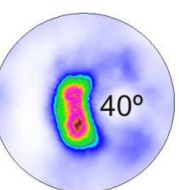

$J_{n}=0.75$

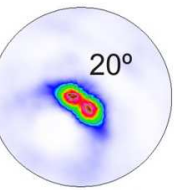

$J_{n}=0.75$
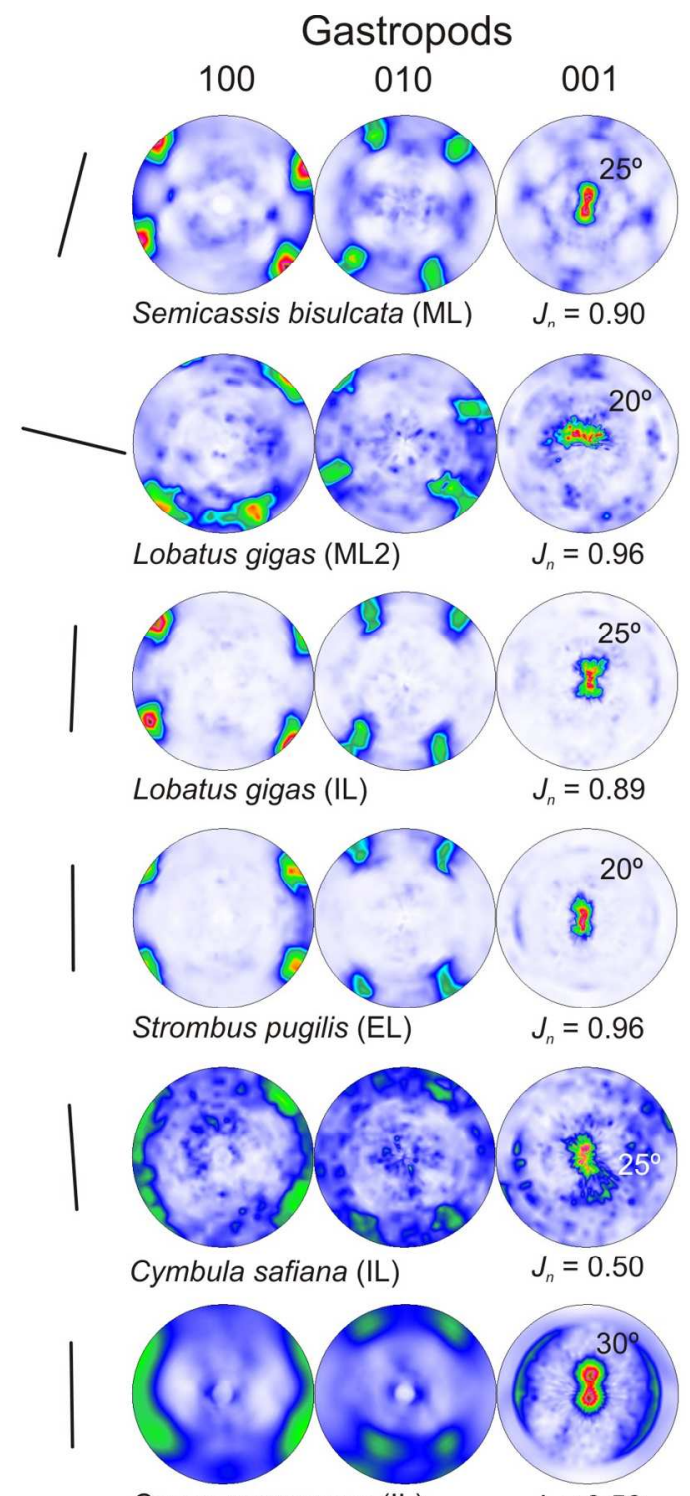

Conus marmoreus (IL)

$J_{n}=0.50$

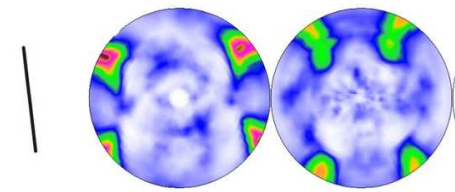

Oliva reticulata (EL)

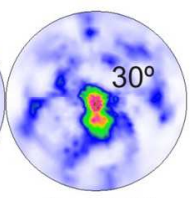

$J_{n}=0.96$

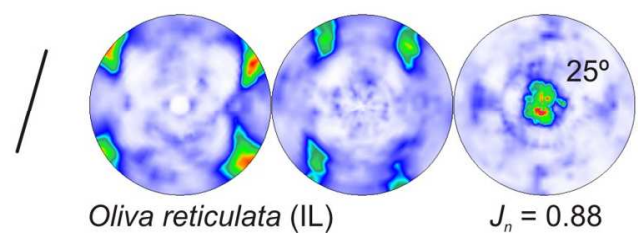

Figure S7. PFs of the molluscan species with 2/4/2 patterns. Bars on the left of PFs represent the orientation of the $1^{\text {st }} \mathrm{OL}$. $J n$ is the texture index. All XRD data. $\mathrm{EL}=$ external layer; $\mathrm{IL}=$ internal layer; $\mathrm{ML}=$ middle layer; $\mathrm{ML2}$ = second middle layer. 

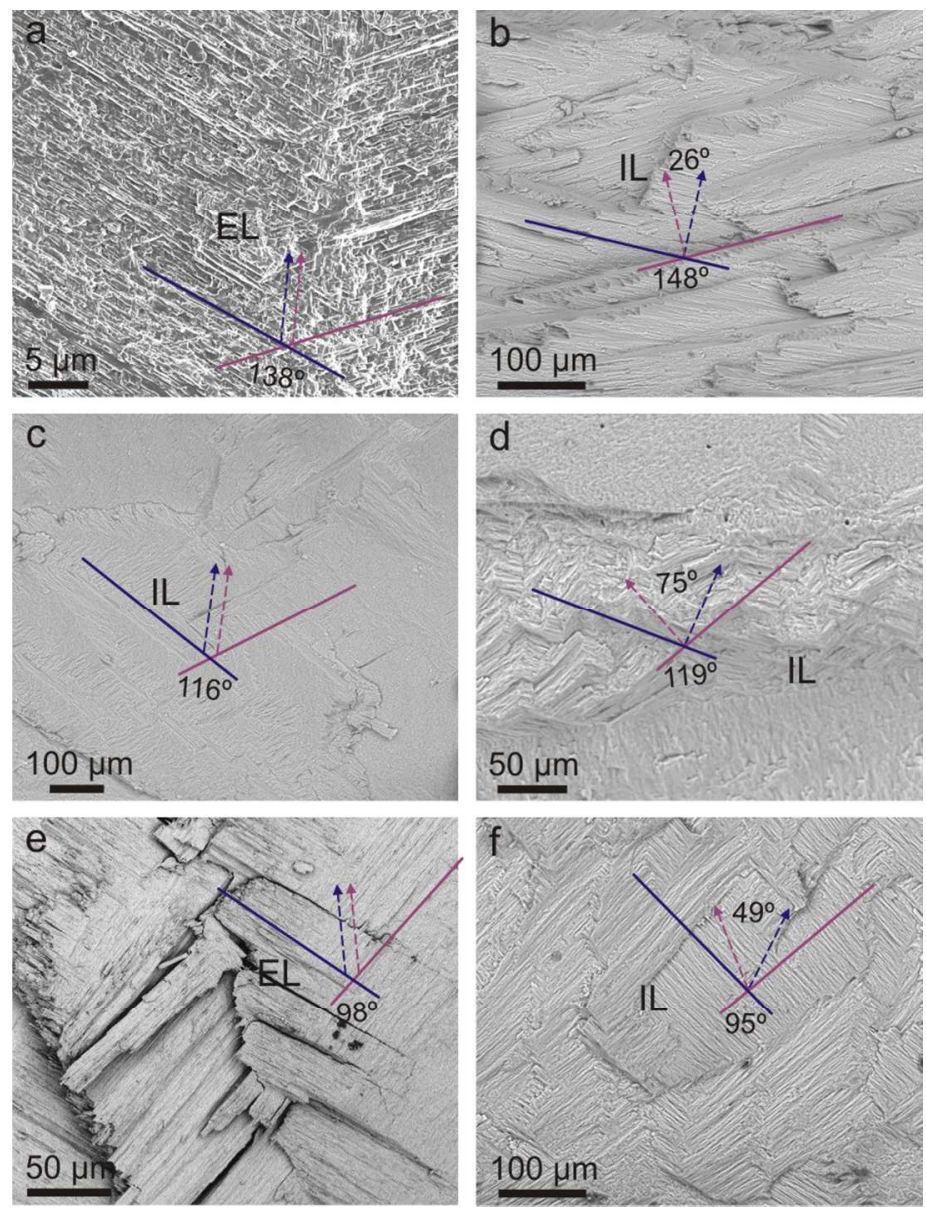

Figure S8. SEM views of fractures parallel to the $1^{\text {st }} \mathrm{OL}$ of the species indicated with arrows in Figure 6. The superimposed sketches and numbers are the orientations of and angles between the $3^{\text {rd }} \mathrm{OL}$ of the adjacent $1^{\text {st }} \mathrm{OL}$, as well as the orientation of and angles between the $c$-axes of the adjacent $1^{\text {st }} \mathrm{OL}$. Colors indicate correspondence between the orientations of $3^{\text {rd }} \mathrm{OL}$ and caxes. (a) Tectus pyramis. (b) Cymbula safiana. (c) Corbula sinensis. (d) Fissurella crassa. (e) Naticidae sp. (f) Laevicardium oblongum. EL = external layer; IL = internal layer. 